\title{
Monitoring aerosol-cloud interactions at the CESAR Observatory in the Netherlands
}

\author{
Karolina Sarna and Herman W. J. Russchenberg \\ TU Delft Climate Institute, Faculty of Civil Engineering and Geotechnology, Delft University of Technology, Stevinweg 1, \\ 2628 CN, Delft, the Netherlands \\ Correspondence to: Karolina Sarna (k.sarna@ @udelft.nl)
}

Received: 2 August 2016 - Discussion started: 2 September 2016

Revised: 7 April 2017 - Accepted: 18 April 2017 - Published: 1 June 2017

\begin{abstract}
The representation of aerosol-cloud interaction (ACI) processes in climate models, although long studied, still remains the source of high uncertainty. Very often there is a mismatch between the scale of observations used for ACI quantification and the ACI process itself. This can be mitigated by using the observations from groundbased remote sensing instruments. In this paper we presented a direct application of the aerosol-cloud interaction monitoring technique (ACI monitoring). ACI monitoring is based on the standardised Cloudnet data stream, which provides measurements from ground-based remote sensing instruments working in synergy. For the data set collected at the CESAR Observatory in the Netherlands we calculate ACI metrics. We specifically use attenuated backscatter coefficient (ATB) for the characterisation of the aerosol properties and cloud droplet effective radius $\left(r_{\mathrm{e}}\right)$ and number concentration $\left(N_{\mathrm{d}}\right)$ for the characterisation of the cloud properties. We calculate two metrics: $\mathrm{ACI}_{r}=\ln \left(r_{\mathrm{e}}\right) / \ln (\mathrm{ATB})$ and $\mathrm{ACI}_{N}=\ln \left(N_{\mathrm{d}}\right) / \ln (\mathrm{ATB})$. The calculated values of $\mathrm{ACI}_{r}$ range from 0.001 to 0.085 , which correspond to the values reported in previous studies. We also evaluated the impact of the vertical Doppler velocity and liquid water path (LWP) on $\mathrm{ACI}$ metrics. The values of $\mathrm{ACI}_{r}$ were highest for $\mathrm{LWP}$ values between 60 and $105 \mathrm{~g} \mathrm{~m}^{-2}$. For higher LWP other processes, such as collision and coalescence, seem to be dominant and obscure the ACI processes. We also saw that the values of $\mathrm{ACI}_{r}$ are higher when only data points located in the updraught regime are considered. The method presented in this study allow for monitoring ACI daily and further aggregating daily data into bigger data sets.
\end{abstract}

\section{Introduction}

Clouds are one of the most important systems for regulating the Earth's radiation. Through changes in their macro- and microphysical properties clouds can significantly affect climate (Ramanathan et al., 1989). Aerosols and their ability to act as cloud condensation nuclei can alter cloud microphysical properties. Twomey (1977) was the first to postulate that increasing pollution, represented by aerosol concentration, leads to an increasing cloud droplet concentration and a decreasing cloud droplet size. The effect of those microphysical changes is increased albedo of the clouds. Despite a good understanding of the physical principles of the aerosol-cloud interaction (ACI) processes, their representation in the climate models remains a source of highest uncertainty (IPCC, 2014).

The conceptual process in which aerosols become activated into cloud droplets is well understood (Lamb and Verlinde, 2011). Also, the influence of the aerosol concentration on the cloud microphysical properties, i.e. cloud droplet size and number concentration, has been studied extensively over the past decades (Feingold et al., 2003; Twohy et al., 2005; Kim et al., 2008; McComiskey et al., 2009) and its existence is not in question. The biggest uncertainty still lies with the scale of the process and it's importance over different locations and in different meteorological conditions. Another source of uncertainty is connected to disentangling the effects of ACI on cloud properties from the effect of cloud thermodynamics and entrainment (Feingold and McComiskey, 2016). McComiskey and Feingold (2012) identified the mismatch in the scale of the ACI process and in the scale of the observations as one of the largest drivers of uncertainty in quantifying $\mathrm{ACI}$. One possible way of overcoming this 
problem is by using the observations from ground-based remote sensing instruments. Ground-based remote sensing instruments are uniquely predisposed to provide high temporal resolution of measurements continuously. At the same time, they can examine the effect of change in aerosol concentration on cloud in a single air column and at the scale of the cloud droplet formation. Ground-based remote sensing instruments are operating at a high temporal and spatial resolution. Hence, it is possible to measure aerosol properties with a ground-based lidar with a high accuracy (Welton et al., 2000 ) and the same is true for cloud droplet observation with the use of cloud radar and radiometer (Knist, 2014).

In the past years several studies used measurements from ground-based remote sensing instruments to quantify ACI (e.g. Feingold et al., 2003; Garrett et al., 2004; Pandithurai et al., 2009; Schmidt et al., 2015). The scope of instruments and measured parameters still differs among them. Further, a great majority of ACI studies are focused on the marine or coastal environment. Although harder to observe, detecting ACI over continents is important in order to make a link between anthropogenic aerosol and the radiative forcing through the ACI process.

A new approach to monitor ACI based on a standardised data format was proposed by Sarna and Russchenberg (2016). Their method (hereafter refereed to as ACI monitoring) is based on the Cloudnet data (Illingworth et al., 2007), a unified data format that is available across the Cloudnet network observatories. ACI monitoring also supplied opensource software (Sarna, 2015) to process data from any Cloudnet station. In this paper we applied this method directly to the data set from the CESAR (Cabauw Experimental Site for Atmospheric Research) Observatory.

The structure of this paper is following: first we briefly present the theoretical framework for calculations, secondly we provide a description of the CESAR Observatory and the used data set. Then we characterise ACI over the CESAR Observatory and describe different drivers of the ACI process at this station. We finish with a summary and conclusions.

\section{Theoretical basis of aerosol-cloud interactions}

The relation between aerosol concentrations and the cloud droplet size was first postulated by Twomey (1977). Using airborne measurements he showed that increasing pollution, and hence an increasing concentration of $\mathrm{CCN}$, will result in clouds with a higher optical thickness. That is measurable only if all other parameters, mainly the amount of available water represented by the liquid water path (LWP), are kept the same. Cloud optical thickness can be related to both the cloud albedo and cloud microphysical properties. Cloud optical thickness $\left(\tau_{\mathrm{d}}\right)$ is proportional to the cloud droplet number concentration $\left(N_{\mathrm{d}}\right)$ (Twomey, 1974)

$\tau_{\mathrm{d}} \propto N_{\mathrm{d}}^{1 / 3}$.
Proxies used to define the aerosol background vary between studies and include parameters such as aerosol number concentration $\left(N_{\mathrm{a}}\right)$, aerosol optical thickness $\left(\tau_{\mathrm{a}}\right)$ and aerosol index. The relation between $N_{\mathrm{d}}$ and $N_{\mathrm{a}}$ was first postulated based on the experimental studies by Twomey and Warner (1967) as

$N_{\mathrm{d}} \propto N_{\mathrm{a}}^{\gamma}$,

where $\gamma$ is the factor with which aerosol number concentration and cloud droplet number concentration depend on each other. The theoretical values of $\gamma$ vary between 0 and 1 . To account for $\gamma$, Feingold et al. (2003) introduced the indirect effect index, which hereafter will be referred to as an ACI metric. It was defined as a relative change in the cloud properties due to changes in the aerosol properties. Based on the relation in Eq. (2) we can say the following:

$\mathrm{ACI}_{N}=\frac{\mathrm{d} \ln N_{\mathrm{d}}}{\mathrm{d} \ln \alpha}, 0<\mathrm{ACI}_{N}<1$,

where $\alpha$ is any of the above-mentioned proxies of the aerosol properties. The value of $\mathrm{ACI}_{N}$ can be related to the value of $\gamma$. To relate aerosol properties to cloud droplet size Feingold et al. (2003) used

$\mathrm{ACI}_{r}=-\left.\frac{\mathrm{d} \ln r_{\mathrm{e}}}{\mathrm{d} \ln \alpha}\right|_{\text {LWP }}, 0<\mathrm{ACI}_{r}<0.33$,

where $r_{\mathrm{e}}$ is the cloud droplet effective radius in the cloud base area. Cloud base area is defined as the range between the cloud base and $30 \mathrm{~m}$ above the cloud base. The bounds of $\mathrm{ACI}_{r}$ between 0 and 0.33 stem from the assumption of a constant LWP when using $r_{\mathrm{e}}$. $\mathrm{ACI}_{N}$ is traditionally not bound by the values of the LWP as it is associated with the activation process which has no direct microphysical relation to the LWP (McComiskey et al., 2009). The relation between $\mathrm{ACI}_{r}$ and $\mathrm{ACI}_{N}$ is described as

$\mathrm{ACI}_{r}=\frac{1}{3} \mathrm{ACI}_{N}$.

Mathematically, both $\mathrm{ACI}_{r}$ and $\mathrm{ACI}_{N}$ are defined as a slope of the regression line between the logarithm of the aerosol property $(\alpha)$ and the logarithm of the cloud property $\left(r_{\mathrm{e}}\right.$ or $\left.N_{\mathrm{d}}\right)$. For this explanation we use $r_{\mathrm{e}}$ as a cloud property. We can define a linear regression between $\ln (\alpha)$ and $\ln \left(r_{\mathrm{e}}\right)$ as

$\ln \left(r_{\mathrm{e}}\right)=a+m \times \ln (\alpha)$,

where $m$ is the slope defined as

$m=r_{\alpha, r_{\mathrm{e}}} \frac{s_{r_{\mathrm{e}}}}{s_{\alpha}}$,

and where $r_{\alpha, r_{\mathrm{e}}}$ is the Pearson product-moment correlation coefficient between $\ln (\alpha)$ and $\ln \left(r_{\mathrm{e}}\right), s_{r_{\mathrm{e}}}$ is the standard deviation of $\ln \left(r_{\mathrm{e}}\right)$ and $s_{\alpha}$ is the standard deviation of $\ln (\alpha)$. The correlations coefficient $r_{\alpha, r_{\mathrm{e}}}$ is defined as

$r_{\alpha, r_{\mathrm{e}}}=\frac{\operatorname{cov}\left(\alpha, r_{\mathrm{e}}\right)}{s_{\alpha} s_{r_{\mathrm{e}}}}$. 
$\operatorname{cov}\left(\alpha, r_{\mathrm{e}}\right)$ is the covariance between $\ln (\alpha)$ and $\ln \left(r_{\mathrm{e}}\right)$. In this study we use ACI monitoring scheme which relies both on the calculation of the correlation coefficient and ACI metrics $\left(\mathrm{ACI}_{N}\right.$ and $\left.\mathrm{ACI}_{r}\right)$.

\section{Methodology of an ACI monitoring scheme}

As we mentioned in previous sections, in this paper we use the aerosol-cloud interaction (ACI) monitoring scheme as described in Sarna and Russchenberg (2016). The core of this method is the Cloudnet data set. It provides a standardised data stream from ground-based remote sensing instruments working in synergy. To be precise, it includes measurements from cloud radar, lidar and microwave radiometer. Although this is a set of instruments present at all observatories within the Cloudnet network, their specifications may vary from station to station.

The Cloudnet data set was designed to facilitate the retrieval of microphysical cloud properties. Therefore, retrieved values of cloud droplet effective radius $\left(r_{\mathrm{e}}\right)$ and cloud droplet number concentration $\left(N_{\mathrm{d}}\right)$ are available from the data set. The microphysical retrieval method used in the Cloudnet data set is based on the method designed by Frisch et al. (2002). In this paper we use the Frisch et al. (2002) retrieval with the assumptions of homogeneous mixing as described in Knist (2014). The aerosol background is represented in the ACI monitoring scheme by an integrated value of the attenuated backscatter coefficient (ATB). The value is integrated from the height of a complete overlap (Kovalev, 2015), which is $120 \mathrm{~m}$ in the set-up of this study, to $300 \mathrm{~m}$ below the cloud base. Measurements of ATB in the area closer to the cloud base than $300 \mathrm{~m}$ are not always reliable and should not be used as an approximation of the aerosol number concentration.

\subsection{Data selection criteria}

Due to the use of cloud microphysical properties the ACI monitoring scheme is applicable only under specific conditions. In particular, only low-level liquid water clouds in well-mixed conditions can be considered. We define the wellmixed condition as a cloud at the top of the boundary layer, where the vertical mixing of the layer is strong. The cloud base should be located below $2000 \mathrm{~m}$ above ground level (AGL). This constraint was chosen as the cloud base of stratocumulus clouds is usually situated below $2000 \mathrm{~m}$ AGL. Due to the integrations of ATB, only clouds with cloud base located above $500 \mathrm{~m}$ AGL are considered. This is because the complete overlap is at $120 \mathrm{~m}$ and data are only considered up to $300 \mathrm{~m}$ below the cloud. ATB should be integrated through at least 2 range gates of the used lidar, which for most Cloudnet observatories are $40 \mathrm{~m}$ wide. Further filtering criteria include the presence of precipitation or drizzle. The Cloudnet data set contains target classification in which liq- uid cloud droplets are categorised specifically (Hogan and O'Connor, 2004). The ACI monitoring scheme selects only data points for which liquid cloud droplets and aerosol are identified. All other data points are disregarded, i.e. all points where any form of precipitation or insects were identified by the Cloudnet classification scheme.

For the data set used in this study, we aggregated daily data into one data set. Data aggregation is only possible if data were collected in similar meteorological conditions. We define the meteorological conditions on the basis of temperature and pressure at the cloud base level. We considered conditions to be similar if the relative standard deviation (rsd) of the measurements is less than 0.1 . The relative standard deviation is defined as a ratio of the standard deviation of the data set to the mean of the data set. As an additional meteorological parameter we use specific humidity. However, the changes in the specific humidity can be larger than those in temperature or pressure. The condition of the constant amount of available water is controlled by the LWP, which represents the total amount of liquid water in the column. It should be noted that meteorological conditions available in the Cloudnet data set come from the KNMI (Koninklijk Nederlands Meteorologisch Instituut) regional atmospheric climate model RACMO (Van Meijgaard et al., 2008) and not from the observations.

\section{Observations from the CESAR Observatory}

The CESAR (Cabauw Experimental Site for Atmospheric Research) Observatory is located in the Netherlands $\left(51.971^{\circ} \mathrm{N}, 4.927^{\circ} \mathrm{E}\right)$ in an area located $0.7 \mathrm{~m}$ below the mean sea level. The site is equipped with a large set of instruments providing constant measurements to study atmospheric processes. The data set used in this study was collected in October-November 2014 during the ACCEPT (Analysis of the Composition of Clouds with Extended Polarization Techniques) campaign. Although the ACCEPT campaign was focused on mixed-phase clouds, multiple measurements of low-level liquid water clouds were also collected. During the 6-week period of the campaign 7 days were represented by a persisting layer of stratocumulus clouds. Due to the requirements of the ACI monitoring scheme, after applying data selection criteria (see Sect. 3.1) only 4 days of data were processed. The total number of measurements profiles used in this study is 1659 . We used one additional requirement: we only processed profiles in which the stratocumulus layer was persisting for at least $30 \mathrm{~min}$. This meant that we only chose data for which at least 60 profiles of $30 \mathrm{~s}$ integrated measurements were consecutive. We chose to add this selection criteria to eliminate days from the aggregated data set for which only a couple of profiles responding to all selection criteria were available. This restriction was applied to avoid profiles that were only temporally fulfilling 
all the selection criteria of this method and in itself might have been part of more turbid conditions.

\subsection{Instrumentation}

One of the main objectives of the ACI monitoring scheme was to develop a method that can be easily applied at various observatories. To achieve that it was necessary to base this method on a widespread set of instruments. Those instruments include cloud radar, lidar and microwave radiometer. In this study we specifically used data from (1) a Ka-band $35.5 \mathrm{GHz}$ cloud radar MIRA, (2) a CHM15X ceilometer operating at $1064 \mathrm{~nm}$ and (3) HATPRO (Humidity and Temperature Profiler) microwave radiometer (MWR) operating at 14 frequencies -7 frequencies between 22 and $31 \mathrm{GHz}(\mathrm{K}-$ band) and 7 frequencies between 51 and $58 \mathrm{GHz}$ (V-Band). Data from the cloud radar MIRA and the HATPRO MWR are used for the retrieval of cloud microphysical properties, specifically cloud droplet effective radius $r_{\mathrm{e}}$ and cloud droplet number concentration $N_{\mathrm{d}}$. Both microphysical parameters are retrieved in accordance with Knist (2014). Data is resampled to an uniform time-height resolution. Time resolution is $30 \mathrm{~s}$ and height resolution (range gate) is $31.2 \mathrm{~m}$.

Moreover, cloud radar MIRA measures the Doppler velocity, which is used to measure updraught within the cloud. Data from HATPRO MWR are also used to measure LWP, which is used to divide data into bins. This division is made in order to consider data in conditions approaching a constant amount of available water. In principle the size of LWP bins should be as small as possible. In order to have a representable data sample we make each bin $15 \mathrm{~g} \mathrm{~m}^{-2}$ wide. Finally, data from the CHM15X ceilometer is used to measure the aerosol concentration. We use the integrated value of the ATB as a proxy of the aerosol concentration (Sarna and Russchenberg, 2016). Table 1 summarises all relevant parameters and the instruments that were used to measure and/or retrieve them. Figure 1 presents the distribution of all measured quantities used in this study.

We use an additional measurement from cloud radar, the Doppler velocity, to measure updraught and downdraught. The ACI metrics are expected to be stronger in the updraught areas, because that is where aerosol is activated into cloud droplets. Figure 2 presents the histogram of Doppler velocity in the aggregated data set. Note that we use the average of Doppler velocity from the cloud base to 2 range gates within the cloud.

\subsection{Aerosol background at CESAR}

A limited number of studies of ACI processes have been focused up to now on the continental low-level liquid water clouds (e.g. Feingold et al., 2003; Ahmad et al., 2013). Most studies were focused on marine or coastal liquid water clouds (e.g. Twohy et al., 2005; McComiskey et al., 2009; Pandithurai et al., 2009). The CESAR Observatory is lo- cated in the western part of the Netherlands. The liquid water clouds observed over CESAR have characteristics of continental clouds. Further, the aerosol background is typically continental. Aerosols over CESAR are mainly represented by an organic aerosol as well as high concentration of ammonium nitrate (Mensah et al., 2012). This type of aerosol background is important to study as it can be directly related to the anthropogenic emissions (Putaud et al., 2004).

\subsection{Selected data set}

As we mentioned in the previous sections, due to the microphysical scale of the ACI processes, data only need to be aggregated under similar meteorological conditions (as defined in Sect. 3.1). This is to make sure that ACI processes are not obscured by other meteorological processes. Figure 3 presents histograms of the meteorological conditions of the aggregated data set. The values of pressure and temperature show a small variation, represented by a small value of the relative standard deviation (rsd), 0.03 for pressure and 0.01 for temperature. The variation of specific humidity is larger, with an rsd of 0.22. To ensure that the amount of available water is constant, we divide data into bins of LWP. It is important to note that for the Cloudnet data set meteorological conditions are provided by the KNMI Regional Atmospheric Climate Model (RACMO; Van Meijgaard et al., 2008).

\section{Results and discussion}

\subsection{ACI metrics}

ACI metrics represent the response of cloud microphysical properties $\left(r_{\mathrm{e}}\right.$ and $\left.N_{\mathrm{d}}\right)$ to aerosol properties (aerosol concentration is represented by ATB). To accurately quantify ACI the amount of available water should be kept constant. To meet this requirement we divide data into bins of LWP. Each LWP bin is $15 \mathrm{~g} \mathrm{~m}^{-2}$ wide. Calculations are made for the bins between 30 and $150 \mathrm{~g} \mathrm{~m}^{-2}$. The lower limit of the LWP analysis range was chosen to be twice the typical uncertainty of the HATPRO MWR measurements $\left(15 \mathrm{~g} \mathrm{~m}^{-2}\right)$. The upper limit is the approximate precipitation threshold (McComiskey et al., 2009). For every LWP bin we also calculate the Pearson product-moment correlation coefficient, $r$ (Eq. 8).

\subsubsection{ACI $_{r}$}

To calculate $\mathrm{ACI}_{r}$ we used Eq. (4). Table 2 compares the calculated values of $\mathrm{ACI}_{r}$ and the correlation coefficient, $r$, for the whole data set and for the updraught regime only. The range of values within the physical limits (between 0 and 0.33 , see Sect. 2) for the whole data set is from 0.001 to 0.085 . These values are in agreement with other studies concerned with quantifying $\mathrm{ACI}_{r}$ in continental clouds. Kim et al. (2008) reported values of $\mathrm{ACI}_{r}$ between 0.04 and 0.17 
Table 1. Cloud and aerosol properties measured or derived from the observations at the CESAR Observatory in the Netherlands.

\begin{tabular}{|c|c|c|}
\hline Measured quantity & Definition & Instrument(s) \\
\hline Cloud liquid water path & $\operatorname{LWP}\left(\mathrm{g} \mathrm{m}^{-2}\right)$ & HATPRO MWR \\
\hline Radar reflectivity factor & $Z\left(\mathrm{dBZ}\right.$ or $\left.\mathrm{m}^{6} \mathrm{~m}^{-3}\right)$ & MIRA \\
\hline Doppler Velocity & $w\left(\mathrm{~m} \mathrm{~s}^{-1}\right)$ & MIRA \\
\hline Cloud droplet effective radius & $r_{\mathrm{e}}(\mu \mathrm{m})($ Knist, 2014) & MIRA/HATPRO MWR \\
\hline Cloud droplet number concentration & $N_{\mathrm{d}}\left(\mathrm{cm}^{-3}\right)($ Knist, 2014) & MIRA/HATPRO MWR \\
\hline Attenuated backscatter coefficient & ATB $\left[\mathrm{m}^{-1} \mathrm{sr}^{-1}\right]$ & CHM15X ceilometer \\
\hline
\end{tabular}
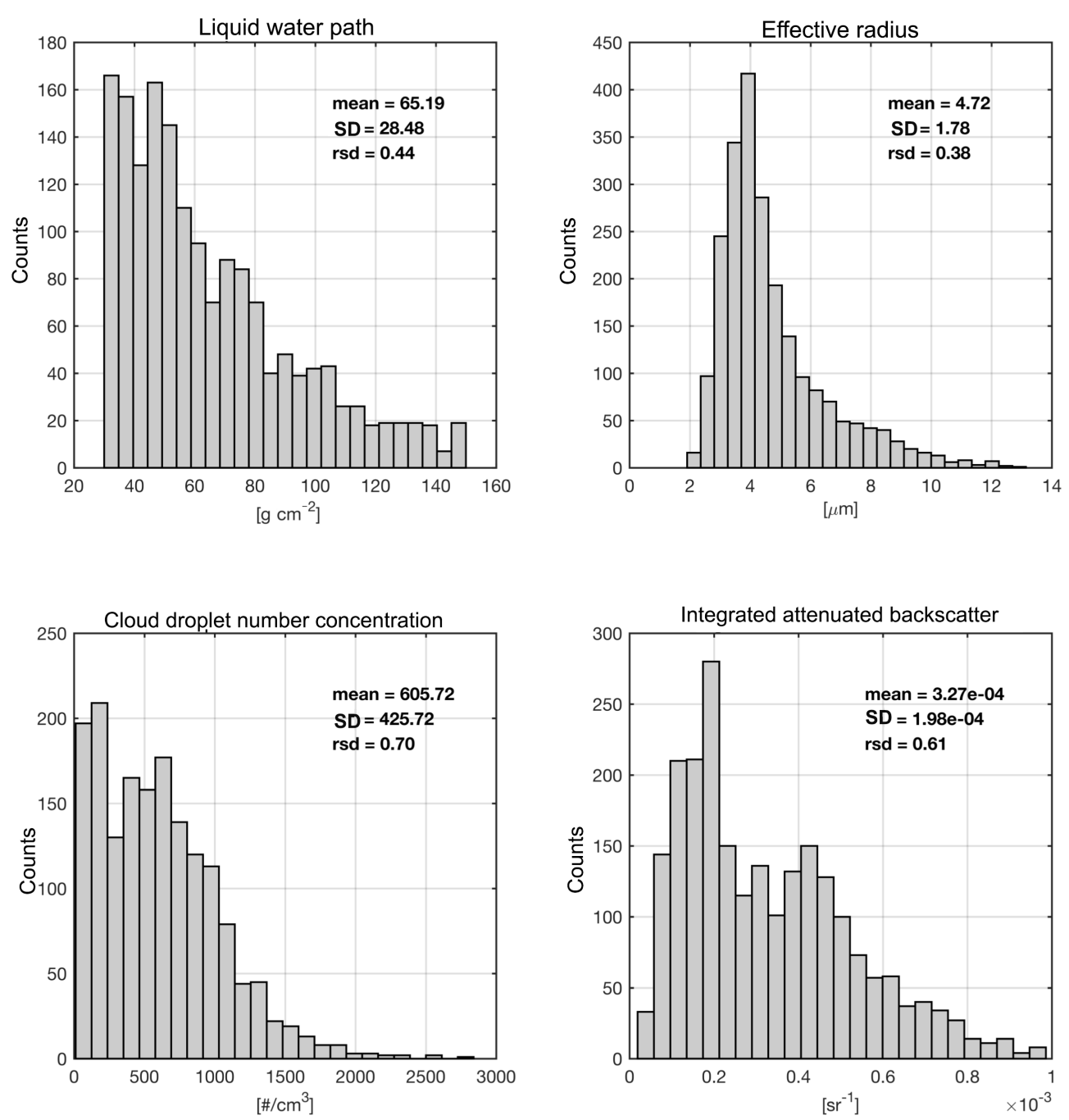

Figure 1. Histograms of the measurements and retrievals for the aggregated data set.

in a study over the ground-based remote sensing site at the Southern Plains in Oklahoma, USA. For the same site, Feingold et al. (2003) reported values of $\mathrm{ACI}_{r}$ between 0.02 and 0.16 . The maximum value of $\mathrm{ACI}_{r}$ calculated in this study is lower than in the above-mentioned studies.

In the data set from the CESAR Observatory we can see that the values of $\mathrm{ACI}_{r}$ are generally within the physical limits for the LWP values from 60 to $135 \mathrm{~g} \mathrm{~m}^{-2}$. This may in- dicate that $\mathrm{ACI}_{r}$ is a process that is significant only for certain values of LWP. When the values of LWP are high, above $135 \mathrm{~g} \mathrm{~m}^{-2}$, other processes within the cloud, such as collision and coalescence, are dominant and obscure the ACI process.

To further investigate the impact of $\mathrm{LWP}$ on $\mathrm{ACI}_{r}$ we selected only the profiles which corresponded to the updraught regime. This was done based on the Doppler velocity. Firstly, it's important to note that the data set is significantly lim- 
Table 2. $\mathrm{ACI}_{r}$ (Eq. 4) together with Pearson product-moment correlation coefficient, $r$, calculated between $\ln \left(r_{\mathrm{e}}\right)$ and $\ln (\mathrm{ATB})$ calculated for the aggregated data set. Data are divided in to bins of LWP. ACI $r$ is calculated for the whole data set and only for the updraught areas. The number of measurements in each bin $(n)$ and the percentage of data available for the updraught only areas are also presented.

\begin{tabular}{|c|c|c|c|c|c|c|c|}
\hline \multirow[b]{2}{*}{ LWP bin } & \multicolumn{3}{|c|}{ Whole data set } & \multicolumn{4}{|c|}{ Only updraught } \\
\hline & $\mathrm{ACI} r$ & $r$ & $n$ & $\mathrm{ACI}_{r}$ & $r$ & $n$ & $\%$ of whole sample \\
\hline $30<\mathrm{LWP}<45$ & 0.016 & -0.038 & 468 & -0.078 & 0.204 & 161 & 34.40 \\
\hline $45<\mathrm{LWP}<60$ & -0.011 & 0.023 & 418 & -0.029 & 0.069 & 133 & 31.82 \\
\hline $60<$ LWP $<75$ & 0.065 & -0.140 & 269 & 0.205 & -0.373 & 69 & 25.65 \\
\hline $75<$ LWP $<90$ & 0.011 & -0.023 & 183 & 0.075 & -0.161 & 48 & 26.23 \\
\hline $90<$ LWP $<105$ & 0.085 & -0.180 & 140 & 0.128 & -0.375 & 37 & 26.43 \\
\hline $105<\mathrm{LWP}<120$ & 0.001 & -0.001 & 76 & 0.271 & -0.730 & 15 & 19.74 \\
\hline $120<\mathrm{LWP}<135$ & 0.046 & -0.068 & 57 & 0.034 & -0.066 & 16 & 28.07 \\
\hline $135<\mathrm{LWP}<150$ & -0.104 & 0.175 & 48 & -0.111 & 0.203 & 13 & 27.08 \\
\hline
\end{tabular}

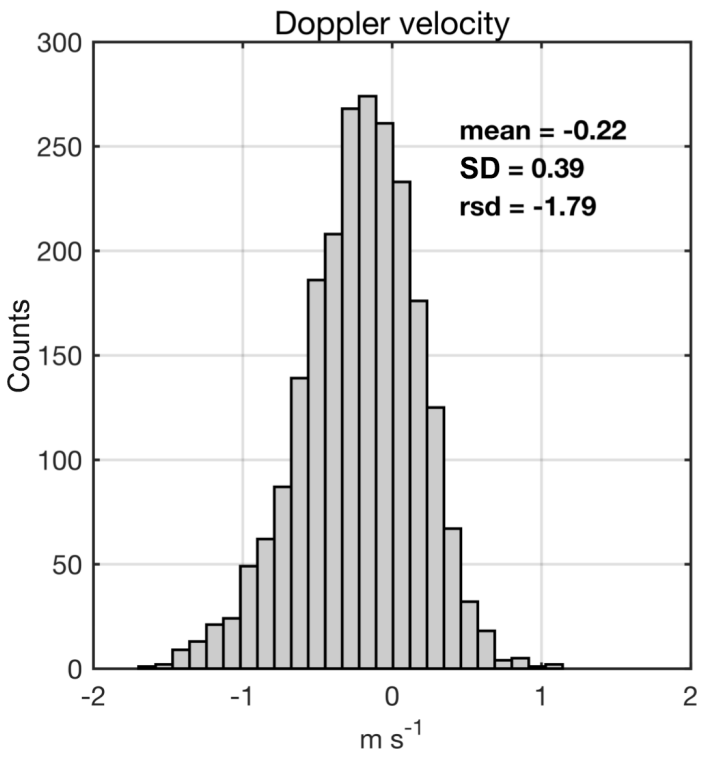

Figure 2. Histograms of the Doppler velocity for the aggregated data set.

ited when considering only the updraught regime: only $30 \%$ of the profiles in the aggregated data set are located in the updraught regime. However, we observe a considerable increase in the value of both $\mathrm{ACI}_{r}$ and the correlation coefficient, $r$. Again, we can see that the values of $\mathrm{ACI}_{r}$ increase with the increasing value of LWP. $\mathrm{ACI}_{r}$ seems to be higher for the values of LWP between 60 and $135 \mathrm{~g} \mathrm{~m}^{-2}$, with an exception of LWP between 75 and $90 \mathrm{~g} \mathrm{~m}^{-2}$. Note that for LWP above $135 \mathrm{~g} \mathrm{~m}^{-2}$ values of $\mathrm{ACI}_{r}$ are exceeding the physical boundaries and indicate that the process is no longer observable. The increase of $\mathrm{ACI}_{r}$ in the updraught regime should be further investigated in a data set with more profiles, as the reduction of the sample size is significant.

\subsection{2 $\operatorname{ACI}_{N}$}

The response of the cloud droplet concentration to the aerosol background is an approximation of the activation process. $\mathrm{ACI}_{N}$ can be directly linked to Eq. (2). We calculate the relative change of $N_{\mathrm{d}}$ with the change of ATB from Eq. (3). For the aggregated data set from CESAR Observatory the value of $\mathrm{ACI}_{N}$ is 0.21 . The value of 0.19 is very small - values reported in the literature often vary between 0.48 and 0.99 (McComiskey et al., 2009, and references within). However, it has been noted before that the size of aerosol may influence the value of $\mathrm{ACI}_{N}$. Smaller aerosol sizes tend to yield smaller $\mathrm{ACI}_{N}$ (McComiskey et al., 2009). Based on the aerosol background at the CESAR Observatory (see Sect. 4.2) we expect the size of the aerosol particles to be smaller. Another possible explanation is that values of $N_{\mathrm{d}}$ used in this study are calculated for the whole cloud and the ACI process is expected mostly in the cloud base and cloud top area. It is also important to note that the retrieval of $N_{\mathrm{d}}$ has very high estimated uncertainties, ranging between 40 and $60 \%$ (Knist, 2014). Those uncertainties are mainly due to the instruments and algorithms errors and were discussed extensively in Knist (2014). In comparison, the uncertainty of the $r_{\mathrm{e}}$ ranges between 10 and $15 \%$. We expect that this high uncertainty is responsible for the low value of $\mathrm{ACI}_{N}$ calculated for the whole data set.

As we mentioned above, based on the theoretical relationships between aerosol and cloud droplets, $\mathrm{ACI}_{N}$ is not dependent on the LWP. However, in this study we decided to test whether there is a dependence of $\mathrm{ACI}_{N}$ on the LWP by dividing data into the same bins of LWP as with the calculation of $\mathrm{ACI}_{r}$. Table 3 presents the comparison of the $\mathrm{ACI}_{N}$ calculated for each LWP bin for the whole data set and only for the updraught regime. What is striking is that, similarly to the case of $\mathrm{ACI}_{r}$, the highest values of $\mathrm{ACI}_{N}$ are present in the range between 60 and $105 \mathrm{~g} \mathrm{~m}^{-2}$. We further selected only the points within the updraught regime. Again, consistently with $\mathrm{ACI}_{r}$, the highest values of $\mathrm{ACI}_{N}$ are noted for the 

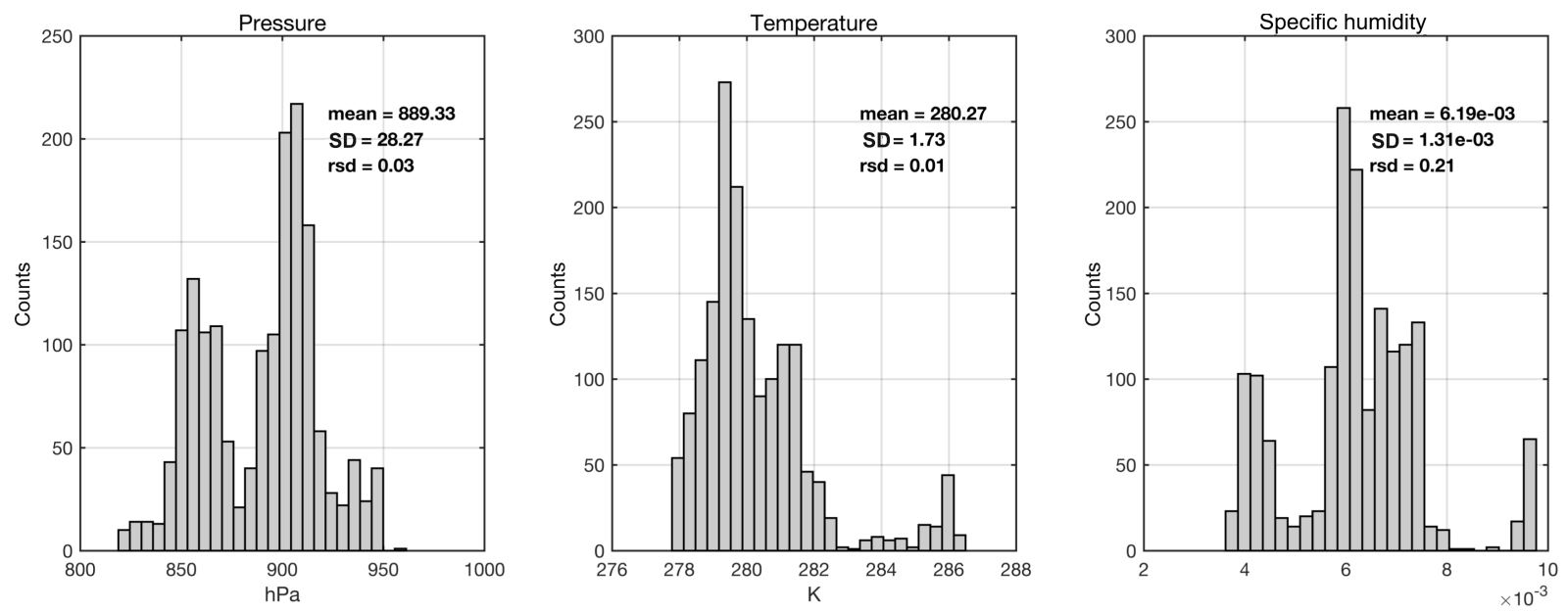

Figure 3. Histograms of the meteorological data for the aggregated data set.

Table 3. $\mathrm{ACI}_{N}$ (Eq. 3) together with Pearson product-moment correlation coefficient, $r$, calculated between $\ln \left(N_{\mathrm{d}}\right)$ and $\ln (\mathrm{ATB})$ calculated for the aggregated data set. Data are divided in to bins of LWP. ACI $N$ is calculated for the whole data set and only for the updraught areas. The number of measurements in each bin $(n)$ and the percentage of data available for the updraught only areas are also presented.

\begin{tabular}{|c|c|c|c|c|c|c|c|}
\hline \multirow[b]{2}{*}{ LWP bin } & \multicolumn{3}{|c|}{ Whole data set } & \multicolumn{4}{|c|}{ Only updraught } \\
\hline & $\mathrm{ACI}_{N}$ & $r$ & $n$ & $\mathrm{ACI}_{N}$ & $r$ & $n$ & $\%$ of whole sample \\
\hline $30<\mathrm{LWP}<45$ & 0.141 & 0.100 & 468 & -0.068 & -0.049 & 161 & 34.40 \\
\hline $45<$ LWP $<60$ & 0.170 & 0.118 & 418 & -0.009 & -0.008 & 133 & 31.82 \\
\hline $60<$ LWP $<75$ & 0.490 & 0.308 & 269 & 0.479 & 0.280 & 69 & 25.65 \\
\hline $75<$ LWP $<90$ & 0.235 & 0.181 & 183 & 0.137 & 0.101 & 48 & 26.23 \\
\hline $90<\mathrm{LWP}<105$ & 0.222 & 0.142 & 140 & 0.326 & 0.268 & 37 & 26.43 \\
\hline $105<\mathrm{LWP}<120$ & -0.034 & -0.021 & 76 & -0.084 & -0.065 & 15 & 19.74 \\
\hline $120<\mathrm{LWP}<135$ & -0.269 & -0.169 & 57 & -0.149 & -0.113 & 16 & 28.07 \\
\hline $135<\mathrm{LWP}<150$ & 0.180 & 0.123 & 48 & 0.041 & 0.038 & 13 & 27.08 \\
\hline
\end{tabular}

LWP between 60 and $75 \mathrm{~g} \mathrm{~m}^{-2}$. For the values LWP above $105 \mathrm{~g} \mathrm{~m}^{-2}$ the increase in the value of ATB no longer corresponds to the increase in the value of $N_{\mathrm{d}}$

$\mathrm{ACI}_{N}$ and $\mathrm{ACI}_{r}$ are theoretically related as in Eq. (5). In the data set analysed in this study this relation is not always present. We expect that the main reason for that is the discrepancy between how $\mathrm{ACI}_{N}$ and $\mathrm{ACI}_{r}$ are calculated. In particular, for the calculation of $\mathrm{ACI}_{r}$ we only use the values of $r_{\mathrm{e}}$ in the cloud base area (defined as the range between the cloud base and $30 \mathrm{~m}$ into the cloud) and for the calculation of $\mathrm{ACI}_{N}$ the value of $N_{\mathrm{d}}$ is derived for the whole cloud. Another important reason might be the high uncertainty of the $N_{\mathrm{d}}$ retrieval. Also, $\mathrm{ACI}_{N}$ is harder to derive. Based on this study, we can say that $\mathrm{ACI}_{r}$ seems to give more realistic results as they are broadly in agreement with the previous studies (see Sect. 5.1.1).

\subsection{Impact of the updraught}

Activation of the aerosol particles into cloud droplets is invigorated in the updraught zones (Altaratz et al., 2014). In this study we identified updraught areas with the use of the Doppler velocity $(w)$. Tables 2 and 3 compare the results of $\mathrm{ACI}_{r}$ and $\mathrm{ACI}_{N}$ calculated for all LWP bins. Both parameters seem to indicate stronger relation between cloud properties $\left(r_{\mathrm{e}}\right.$ and $\left.N_{\mathrm{d}}\right)$ and aerosol properties (ATB) in the updraught areas. This is implicated by the increase of both the ACI metrics as well as the correlation coefficients. The invigoration of ACI processes in the updraught regime was also reported in previous studies (Schmidt et al., 2015). It is important to note that the number of available profiles is greatly diminished by the selection of updraught areas only. Specifically, the number of profiles in the updraught regime are reduced by $70 \%$ compared to all the selected profiles. The number of samples in LWP bins over $105 \mathrm{~g} \mathrm{~m}^{-2}$ is too small to make significant conclusions. However, we can clearly observe that both $\mathrm{ACI}_{r}$ and $\mathrm{ACI}_{N}$ have the highest values in the LWP bins between 60 and $105 \mathrm{~g} \mathrm{~m}^{-2}$. 


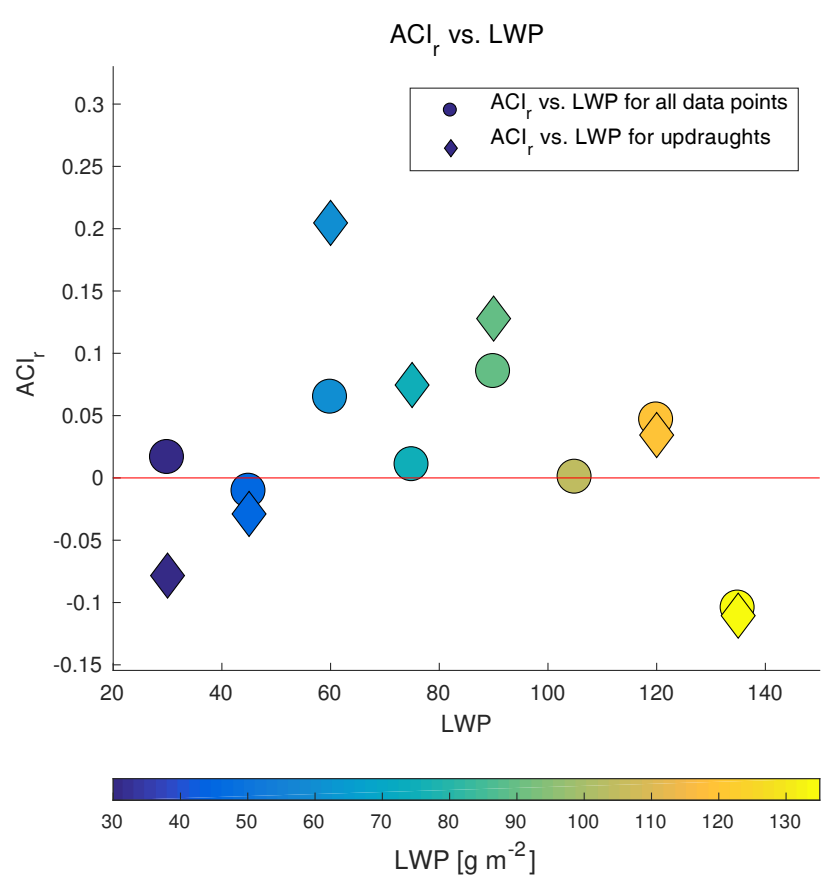

Figure 4. Scatter plot between $\mathrm{ACI}_{r}$ and $\mathrm{LWP}$ for all data points and the data points located in the updraught areas in the aggregated data set.

\subsection{Relation with LWP}

One of the conditions for observing changes in microphysical properties of clouds due to an aerosol number concentration initially postulated by Twomey (1977) was the constant amount of water available. Over the past decades different studies used that conditions with liberty. In the satellite remote sensing quantification of ACI the constraint of LWP is often omitted (e.g. Kaufman et al., 2005). In the groundbased remote sensing methods the constraint on LWP is kept, but the size of LWP bins varies greatly. The division into LWP bins is important as it is still not clear if ACI is a significant process in different LWP regimes.

In this study we divided data into LWP bins $15 \mathrm{~g} \mathrm{~m}^{-2}$ wide. This was the lowest width of the bin that was allowed by the instrument restrictions (see Sect. 4.1). We saw significant changes in the calculated values of both $\mathrm{ACI}_{r}$ and $\mathrm{ACI}_{N}$ in different LWP bins. When the considered LWP bins are wider, those differences are not visible and it is difficult to define the conditions that invigorate the ACI processes. The drawback of applying small bins is the sample size. However, what we wanted to present with this method is the variety of values in different bins. Figure 4 presents the values of $\mathrm{ACI}_{r}$ plotted against LWP for both the whole data set and the selected profiles in the updraught regime. We can observe an increase of $\mathrm{ACI}_{r}$ with LWP in the range between 60 and $105 \mathrm{~g} \mathrm{~m}^{-2}$ for both the updraught and the whole data set. $\mathrm{ACI}_{r}$ reaches values outside of the physical boundaries

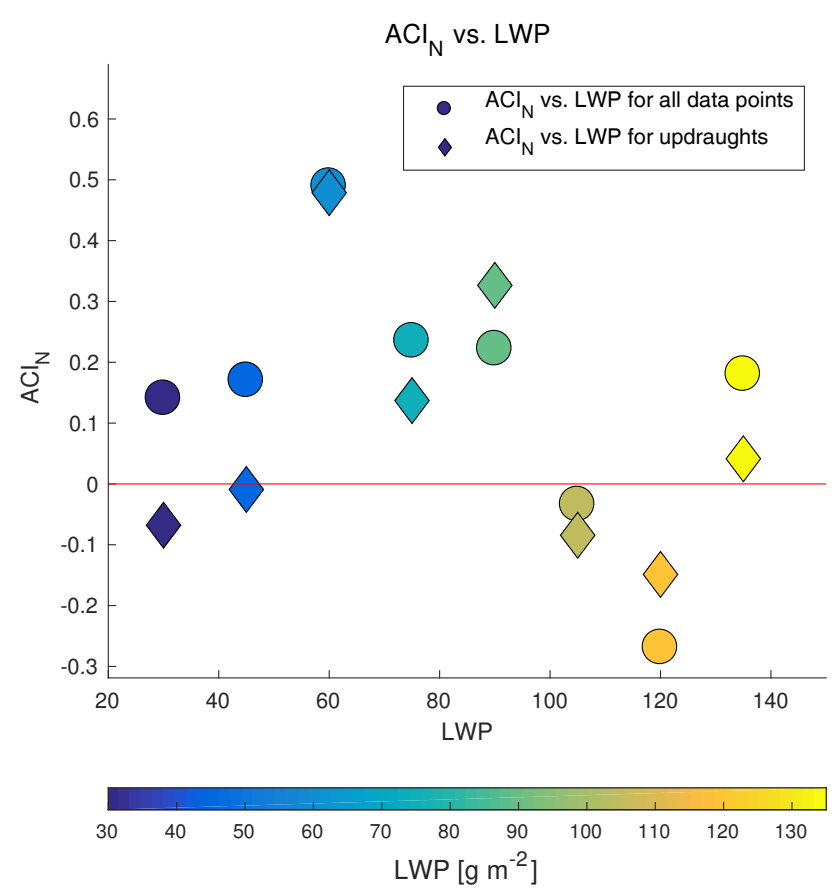

Figure 5. Scatter plot between $\mathrm{ACI}_{N}$ and LWP for the data points located in the updraught areas of the aggregated data set.

for LWP that are either very low (30 to $60 \mathrm{~g} \mathrm{~m}^{-2}$ ) or very high (135 to $150 \mathrm{~g} \mathrm{~m}^{-2}$ ). This may indicate that the ACI processes are only observable in certain LWP conditions. Importantly, this is even more pronounced in the updraught regime. It should be noted that the negative values of $\mathrm{ACI}_{r}$ can also be caused by the small sample size and the errors in the retrieval of $r_{\mathrm{e}}$. Figure 5 presents the values of $\mathrm{ACI}_{N}$ plotted against LWP for both the whole data set and the selected profiles in the updraught regime. The most striking observation here is that the value of $\mathrm{ACI}_{N}$ in the updraught regime is lower in the majority of the LWP bins than in the whole data set, unlike in the case of $\mathrm{ACI}_{r}$ where the updraught regime is related with the higher values of $\mathrm{ACI}_{r}$ in comparison to the whole data set. A possible explanation for this phenomenon is, like we mentioned before, the difference in the calculation method: $\mathrm{ACI}_{r}$ is calculated for the cloud base region only, whereas $\mathrm{ACI}_{N}$ is calculated for the whole cloud.

\subsection{Relation between correlation coefficient $(r)$ and $\mathbf{A C I}_{r}$}

Most of the studies concerned with aerosol-cloud interactions calculate either $\mathrm{ACI}_{r}$ (Eq. 4), $\mathrm{ACI}_{N}$ (Eq. 3) or both to quantify the relationship between aerosol and cloud properties. As we explained before, in mathematical terms $\mathrm{ACI}_{r}$ and $\mathrm{ACI}_{N}$ are a slope of the regression line calculated between the natural logarithm of the aerosol properties and a natural logarithm of the cloud properties. The aerosol property is treated as the independent variable and the cloud prop- 


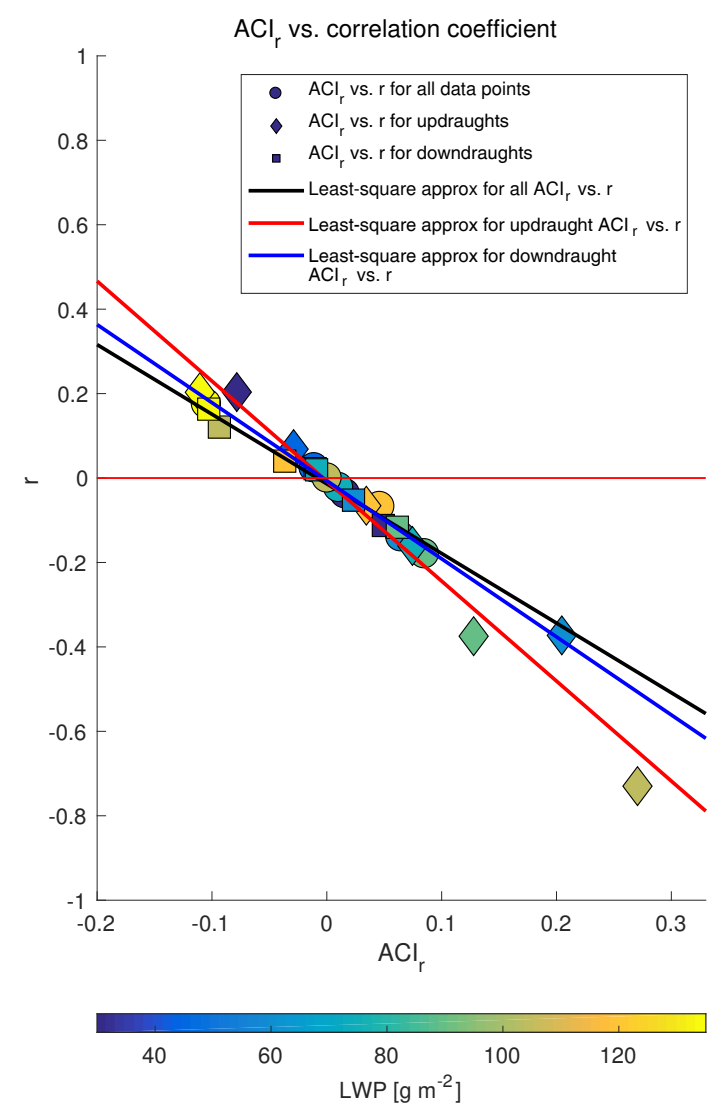

Figure 6. Scatter plot between $\mathrm{ACI}_{r}$ and the Pearson productmoment correlation coefficient, $r$.

erty is the dependent variable. As we shown in Sect. 2, correlation coefficient and slope of the regression line are related as in Eq. (6).

For the data set from the CESAR Observatory we compared the values of $\mathrm{ACI}_{r}$ with the values of the correlation coefficient. We did this comparison for every LWP bin for the whole data set and then separately only for the profiles corresponding to the updraught area and to the downdraught area. Figure 6 presents the scatter plot between $\mathrm{ACI}_{r}$ and the correlation coefficient. We can observe that most of the values of $\mathrm{ACI}_{r}$ that fall outside of the physical bounds are observed for the downdraught areas of the whole data set or for the very small or very high bins of the LWP. This further underlines the impact of the updraught and LWP on the aerosol-cloud interactions.

The relation between the correlation coefficient and $\mathrm{ACI}_{r}$ is mathematically sound. However, it is not often presented in the literature. Based on the analysed data set we can say that the lower the value of the correlation coefficient between aerosol and cloud properties, the higher the calculated value of the $\mathrm{ACI}_{r}$. However, this relation between the two parameters is only significant when data is sampled at a high temporal and spatial resolution and divided into bins of LWP to simulate the condition of a constant amount of available water. In the case of no constraint on LWP or data with a low spatial resolution (i.e. satellite remote sensing aggregated data sets) the calculation of the correlation coefficient will become irrelevant as the variance of the data set will be minimised by the aggregation (McComiskey and Feingold, 2012). In the case of the ACI monitoring scheme calculating both $\mathrm{ACI}_{r}$ and the correlation coefficient is relevant, as data is collected with a temporal and spatial resolution that corresponds to the scale of the aerosol-cloud interaction processes.

\section{Summary and conclusions}

In this paper we presented a direct application of the aerosolcloud interaction monitoring scheme as presented in Sarna and Russchenberg (2016). We used a Cloudnet data set from the CESAR Observatory in the Netherlands. Data were collected during the ACCEPT measurement campaign in October-November 2014. We aggregated daily measurements into one data set based on the similar meteorological conditions. We only considered non-precipitating, lowlevel liquid water clouds. All forms of precipitation were disregarded based on the Cloudnet target categorisation. Investigated clouds had the cloud base located between 500 and $2000 \mathrm{~m}$ above ground level. Lastly, we only used periods when conditions corresponding to the above-mentioned criteria were persisting for at least $30 \mathrm{~min}$.

For the aggregated data set we calculated ACI metrics using cloud droplet effective radius $\left(r_{\mathrm{e}}\right)$ following Eq. (4) and cloud droplet number concentration $\left(N_{\mathrm{d}}\right)$ following Eq. (3). The aerosol properties were represented by the integrated ATB. For both ACI metrics we also calculate Pearson's moment correlation coefficient, $r$. For all the above-mentioned calculations data were divided into bins of LWP, where every bin was $15 \mathrm{~g} \mathrm{~m}^{-2}$ wide. The calculated values of $\mathrm{ACI}_{r}$ ranged from 0.001 to 0.085 , which correspond with the values reported in the previous studies. For the low (between 30 and $60 \mathrm{~g} \mathrm{~m}^{-2}$ ) and high (above $135 \mathrm{~g} \mathrm{~m}^{-2}$ ) values of LWP we observed negative, values of $\mathrm{ACI}_{r}$, which were therefore outside of the physical bounds,. This is an indication that the ACI processes are not easily observable in those LWP conditions and are possibly obscured by other cloud processes. The values of $\mathrm{ACI}_{N}$ were significantly lower than those reported in the literature. We attribute that to two reasons. Firstly, the retrieval of $N_{\mathrm{d}}$ is susceptible to high error, varying between 40 and $60 \%$ due to instrument errors and retrieval assumptions. Secondly, the aerosol background over the CESAR Observatory is characteristic of the continental aerosol background whereas most studies calculating $\mathrm{ACI}_{N}$ are located in the marine or coastal areas. The size of continental aerosol is significantly smaller which can lead to smaller values of $\mathrm{ACI}_{N}$. Further, the $\mathrm{ACI}_{N}$ is calculated considering the information from the whole cloud profile, whereas $\mathrm{ACI}_{r}$ is calcu- 
lated only in the cloud base area, where the ACI processes are the strongest. Considering the high uncertainty of the $N_{\mathrm{d}}$ retrieval, we recommend calculating $\mathrm{ACI}_{r}$ to account for the impact of aerosol on the cloud microphysical properties.

We also evaluated the impact of the vertical wind speed at the cloud base and LWP on ACI metrics. In the analysed data set both of those parameters showed a clear impact on the values of $\mathrm{ACI}_{r}$. The values of $\mathrm{ACI}_{r}$ were highest for the LWP between 60 and $105 \mathrm{~g} \mathrm{~m}^{-2}$. For the higher values of LWP other processes, such as collision and coalescence, seem to be dominant and obscure the ACI processes. This may indicate that the approximated precipitation threshold $\left(150 \mathrm{~g} \mathrm{~m}^{-2}\right)$ should be lowered and the Cloudnet target categorisation re-evaluated. The values of $\mathrm{ACI}_{r}$ are higher when only data points located in the updraught regime were considered. As indicated in previous studies, the updraught is an important factor in invigorating aerosol-cloud interactions. The values of $\mathrm{ACI}_{r}$ in the downdraught regime were often outside of the physical bounds. It is desirable to only consider data points located within the updraught regime. However, it should be noted that selecting the updraught regime only significantly decreases the data sample size.

The ACI metrics are used to account for the proportionality factor between aerosol number concentration and cloud droplet number concentration (Eq. 2). In this study we explained that the correlation coefficient and ACI metrics can be related to the high-resolution data set, as ACI metrics are the slope of the regression line between cloud and aerosol properties. Therefore, a lower value of the correlation coefficient will indicate the increase of the $\mathrm{ACI}_{r}$.

The method presented in this study allows for monitoring aerosol-cloud interactions daily and further aggregating daily data into bigger data sets. We showed that it can be easily implemented at any observatory using Cloudnet data format. However, one should keep in mind that the specific conditions between the stations may vary and combining data points from various stations should be made only after assessing each of them separately. The method described in this paper could be implemented at each station separately and then the results from observatories could be combined and compared with similar conditions. Such a comparison would be very valuable, leading to a better understanding of the aerosol-cloud interactions, but it was beyond the scope of this research project. A widespread network of ACI monitoring could lead to estimating the drivers of this process more accurately in various conditions. This methodology was developed with a purpose of integration into the Cloudnet network products. Further, as the methodology presented here is based on the remote sensing instruments only, it could be adapted to the satellite remote sensing and observation of ACI processes in the cloud top area. Such an adaptation would have to be done with care and account for all the requirements of the data selection necessary for this method.
Data availability. The data set used in this study was provided by the Leibniz-Institut für Troposphärenforschung (TROPOS) and can be obtained by contacting Patric Seifert (seifert@tropos.de).

Competing interests. The authors declare that they have no conflict of interest.

Acknowledgements. The research leading to these results received funding from the European Union Seventh Framework Programme (FP7/2007-2013) under grant agreement 262254. The authors would like to acknowledge and thank Patric Seifert from the Leibniz-Institut für Troposphärenforschung (TROPOS) and Lukas Pfitzenmaier from Delft University of Technology for providing the data set from the ACCEPT campaign used in this study.

Edited by: A. Macke

Reviewed by: two anonymous referees

\section{References}

Ahmad, I., Mielonen, T., Grosvenor, D. P., Portin, H. J., Arola, A., Mikkonen, S., Kühn, T., Leskinen, A., Joutsensaari, J., Komppula, M., Lehtinen, K. E. J., Laaksonen, A., and Romakkaniemi, S.: Long-term measurements of cloud droplet concentrations and aerosol-cloud interactions in continental boundary layer clouds, Tellus B, 65, 20138, doi:10.3402/tellusb.v65i0.20138, 2013.

Altaratz, O., Koren, I., Remer, L., and Hirsch, E.: Review: Cloud invigoration by aerosols-Coupling between microphysics and dynamics, Atmospheric Research, 140-141, 38-60, doi:10.1016/j.atmosres.2014.01.009, 2014.

Feingold, G. and McComiskey, A.: ARM's Aerosol-CloudPrecipitation Research (Aerosol Indirect Effects), Meteorol. Monogr., 57, 22.1-22.15, doi:10.1175/AMSMONOGRAPHSD-15-0022.1, 2016.

Feingold, G., Eberhard, W. L., Veron, D. E., and Previdi, M.: First measurements of the Twomey indirect effect using ground-based remote sensors, Geophys. Res. Lett., 30, 1287, doi:10.1029/2002GL016633, 2003.

Frisch, S., Shupe, M., Djalalova, I., Feingold, G., and Poellot, M.: The Retrieval of Stratus Cloud Droplet Effective Radius with Cloud Radars, J. Atmos. Ocean. Technol., 19, 835-842, doi:10.1175/1520-0426(2002)019<0835:TROSCD>2.0.CO;2, 2002.

Garrett, T. J., Zhao, C., Dong, X., Mace, G. G., and Hobbs, P. V.: Effects of varying aerosol regimes on low-level Arctic stratus, Geophys. Res. Lett., 31, L17105, doi:10.1029/2004GL019928, 2004.

Hogan, R. J. and O'Connor, E. J.: Facilitating cloud radar and lidar algorithms: the Cloudnet Instrument Synergy/Target Categorization product, 2004.

Illingworth, A. J., Hogan, R. J., O’Connor, E. J., Bouniol, D., Delanoë, J., Pelon, J., Protat, A., Brooks, M. E., Gaussiat, N., Wilson, D. R., Donovan, D. P., Baltink, H. K., van Zadelhoff, G.J., Eastment, J. D., Goddard, J. W. F., Wrench, C. L., Haeffelin, M., Krasnov, O. A., Russchenberg, H. W. J., Piriou, J.-M., Vinit, 
F., Seifert, A., Tompkins, A. M., and Willén, U.: Cloudnet, B. Am. Meteorol. Soc., 88, 883-898, doi:10.1175/BAMS-88-6-883, 2007.

IPCC: Climate Change 2013 - The Physical Science Basis: Working Group I Contribution to the Fifth Assessment Report of the Intergovernmental Panel on Climate Change, Cambridge University Press, Cambridge, 2014.

Kaufman, Y. J., Koren, I., Remer, L. A., Rosenfeld, D., and Rudich, Y.: The effect of smoke, dust, and pollution aerosol on shallow cloud development over the Atlantic Ocean, P. Natl. Acad. Sci. USA, 102, 11207-11212, doi:10.1073/pnas.0505191102, 2005.

Kim, B.-G., Miller, M. A., Schwartz, S. E., Liu, Y., and Min, Q.: The role of adiabaticity in the aerosol first indirect effect, J. Geophys. Res., 113, D05210, doi:10.1029/2007JD008961, 2008.

Knist, C. L.: Retrieval of liquid water cloud properties from groundbased remote sensing observations, PhD thesis, TU Delft: Civil Engineering and Geosciences: Geoscience and Remote Sensing, 2014.

Kovalev, V. A.: Solutions in LIDAR Profiling of the Atmosphere, John Wiley \& Sons, 2015.

Lamb, D. and Verlinde, J.: Physics and Chemistry of Clouds, Cambridge University Press, 2011.

McComiskey, A. and Feingold, G.: The scale problem in quantifying aerosol indirect effects, Atmos. Chem. Phys., 12, 1031-1049, doi:10.5194/acp-12-1031-2012, 2012.

McComiskey, A., Feingold, G., Frisch, A. S., Turner, D. D., Miller, M. A., Chiu, J. C., Min, Q., and Ogren, J. A.: An assessment of aerosol-cloud interactions in marine stratus clouds based on surface remote sensing, J. Geophys. Res., 114, D09203, doi:10.1029/2008JD011006, 2009.

Mensah, A. A., Holzinger, R., Otjes, R., Trimborn, A., Mentel, T. F., ten Brink, H., Henzing, B., and Kiendler-Scharr, A.: Aerosol chemical composition at Cabauw, The Netherlands as observed in two intensive periods in May 2008 and March 2009, Atmos. Chem. Phys., 12, 4723-4742, doi:10.5194/acp-12-4723-2012, 2012.

Pandithurai, G., Takamura, T., Yamaguchi, J., Miyagi, K., Takano, T., Ishizaka, Y., Dipu, S., and Shimizu, A.: Aerosol effect on cloud droplet size as monitored from surface-based remote sensing over East China Sea region, Geophys. Res. Lett., 36, L13805, doi:10.1029/2009GL038451, 2009.

Putaud, J.-P., Raes, F., Van Dingenen, R., Brüggemann, E., Facchini, M.-C., Decesari, S., Fuzzi, S., Gehrig, R., Hüglin, C., Laj, P., Lorbeer, G., Maenhaut, W., Mihalopoulos, N., Müller, K., Querol, X., Rodriguez, S., Schneider, J., Spindler, G., ten Brink, H., Tørseth, K., and Wiedensohler, A.: A European aerosol phenomenology - 2: chemical characteristics of particulate matter at kerbside, urban, rural and background sites in Europe, Atmos. Environ., 38, 2579-2595, doi:10.1016/j.atmosenv.2004.01.041, 2004.
Ramanathan, V., D., C. R., Harrison, E. F., Minnis, P., Barkstrom, B. R., Ahmad, E., and Hartmann, D.: Cloud-Radiative Forcing and Climate: Results from the Earth Radiation Budget Experiment, Science, 243, 57-63, doi:10.1126/science.243.4887.57, 1989.

Sarna, K.: ACI monitoring: First release, doi:10.5281/zenodo.32033, 2015.

Sarna, K. and Russchenberg, H. W. J.: Ground-based remote sensing scheme for monitoring aerosol - cloud interactions, Atmos. Meas. Tech., 9, 1039-1050, doi:10.5194/amt-9-1039-2016, 2016.

Schmidt, J., Ansmann, A., Bühl, J., and Wandinger, U.: Strong aerosol-cloud interaction in altocumulus during updraft periods: lidar observations over central Europe, Atmospheric Chemistry and Physics, 15, 10687-10700, doi:10.5194/acp-15-10687-2015, 2015.

Twohy, C. H., Petters, M. D., Snider, J. R., Stevens, B., Tahnk, W., Wetzel, M., Russell, L., and Burnet, F.: Evaluation of the aerosol indirect effect in marine stratocumulus clouds: Droplet number, size, liquid water path, and radiative impact, J. Geophys. Res., 110, D08203, doi:10.1029/2004JD005116, 2005.

Twomey, S.: Pollution and the planetary albedo, Atmos. Environ., 8, 1251-1256, doi:10.1016/0004-6981(74)90004-3, 1974.

Twomey, S.: The Influence of Pollution on the Shortwave Albedo of Clouds, J. Atmos. Sci., 34, 1149-1152, doi:10.1175/15200469(1977)034<1149:TIOPOT>2.0.CO;2, 1977.

Twomey, S. and Warner, J.: Comparison of Measurements of Cloud Droplets and Cloud Nuclei, J. Atmos. Sci., 24, 702-703, doi:10.1175/1520-0469(1967)024<0702:COMOCD>2.0.CO;2, 1967.

Van Meijgaard, E., Van Ulft, L., Van de Berg, W., Bosveld, F., Van den Hurk, B., Lenderink, G., and Siebesma, A.: The KNMI regional atmospheric climate model RACMO version 2.1, Koninklijk Nederlands Meteorologisch Instituut, 2008.

Welton, E. J., Voss, K. J., Gordon, H. R., Maring, H., Smirnov, A., Holben, B., Schmid, B., Livingston, J. M., Russell, P. B., Durkee, P. A., Formenti, P., and Andreae, M. O.: Ground-based lidar measurements of aerosols during ACE-2: instrument description, results, and comparisons with other ground-based and airborne measurements, Tellus B, 52, 636-651, doi:10.1034/j.16000889.2000.00025.x, 2000 . 